\title{
What do we Talk about when we Talk about Ethics? A Research Journey through the World Most Ethical Companies
}

\author{
Dr. Ana Roque ${ }^{1 *}$, Professor José Manuel Moreira ${ }^{2}$, Professor José Dias Figueiredo ${ }^{1}$, Professor \\ Rosana Albuquerque ${ }^{3}$ \\ ${ }^{1}$ CEG-IST, Instituto Superior Técnico, Universidade de Lisboa, Av. Rovisco Pais, 1049 - 001 Lisboa, Portugal. \\ ${ }^{2}$ Universidade de Aveiro \\ ${ }^{3}$ Departamento de Ciências Sociais e de Gestão; Centro de Estudos das Migrações e Relações Interculturais \\ CEMRI - Universidade Aberta, Rua da Escola Politécnica, 141-147, 1269-001 Lisboa, Portugal.
}

*Corresponding Author: Dr. Ana Roque, CEG-IST, Instituto Superior Técnico, Universidade de Lisboa, Av. Rovisco Pais, 1049 - 001 Lisboa, Portugal.

\begin{abstract}
:
How can an ethical-driven company be defined?

This paper presents a possible model for an ethical-driven company designed according to the Ethisphere Institute selection survey for the World Most Ethical Companies.

The paper also presents how ethics is internalized in companies considered excellent in this field, through the analysis of primary date like companies' activity reports (annual, sustainability, ethics).

We use a qualitative approach since what is intended is not to know what the companies do but how they do it. The research method was the Grounded Theory and the content analysis was done using MAXQDAsoftware.

The analysis shows inconsistencies in the use of the word ethics and lack of clarity about what is and what may be the role of ethics in organizations. It also shows that most companies are still in a "compliance mode", with no real incorporation of ethics in their strategy and core issues. The key point for a decisive ethics incorporation seems to be the adoption of a purpose that encourages action, beyond profitability.

Keywords: Compliance, Ethics, Ethical-driven Companies, Grounded Theory, World Most Ethical Companies, Companies Ethical Performance
\end{abstract}

\section{INTRODUCTION}

\subsection{Ethics as a Necessary Condition for Sustainable Development}

Managing the ethical performance of a company is always complex because we are talking about behaviors, and "although patterns of behavior may be predictable, individual behavior at a specific time is not predictable" [1]. So how should the design of an ethical company progress? We would say, as the cat replied to Alice in Lewis Carroll novel, "that depends a good deal on where you want to get to", and we want to go for a sustainable development.

According to Wesaratet al "The effectiveness of implementing sustainable development programs may depend on the degree to which companies emphasize organizational ethics"[2], on the companies's "Commitment to behave ethically" as Kaptein[3] stated in his Ethical Virtues Model.And how are the companies that assume this commitment? How is ethics reflected in each of the company's operations in light of this commitment?

Our starting point was Ethisphere Institute's World Most Ethical Companies. We analysed the selection survey to reach a portrait of a model company in terms of ethics' relevance then through the analysis of distinguished companies' corporate communication, we tried to understand the state of the art in corporate ethics.

The aim of this study is to identify what is the paradigm in terms of business ethics management through Ethisphere Institute's vision and understand how ethics is lived in the companies considered to be excellent in the field. 
A little warning: as Aristotle pointed out, at the Olympics "the most admirable and the strongest are not the ones who are crowned, but those who compete for victory" [4], also here the fact that a company is part of the "World Most Ethical Companies" does not mean that it is the most ethical, but that it has applied and met the criteria, which, nonetheless, should not be overlooked.

\subsection{Ethics and Compliance}

The junction of ethics and compliance is the most common in companies, in fact "In practice, many, if not most, practitioners have both Compliance and Ethics Responsibilities"[5]. Therefore, in many studies, the term is used interchangeably to denote who cares for one or the other area or both. And indeed, ethics and compliance officers, together or separately, have common challenges, and one of those challenges in many companies is fighting the lack of legitimacy, and the perceived lack of relevance to the business: "because Ethics and Compliance are often seen as clashing with dominant business imperatives”[5].

For all these reasons, "drawing a distinction between the two concepts may seem unimportant. (...) Indeed, the conscious choices that companies make about these concepts often define their business"[6]. This is also our understanding, and since Ethisphere itself refers to the function as the "person assigned overall responsibility for ethics and compliance," we thought it would be important to distinguish the two here so that it is clear which one is our object of study.

This need to clarify the words also arises in other studies: "The conflation of "business ethics" and "ethics and compliance" also needs to be addressed by both scholars and practitioners. While compliance managers and their related professional organizations have claimed the "ethics" nomenclature, CSR managers described practices informed by ethical aspirations beyond legal requirements.'[7].

According to the Ethics Institute and the Institute of Business Ethics [8], ethics and compliance have distinguished, but yet parallel, functions: "If the definition of compliance is focused on laws and rules, the key element of business ethics is values"[8], "compliance is something that the government requires you to do. Ethics, on the other hand, is something you choose to consider when taking action"[6].

To put it in practical terms, when a company enters a new country, the role of the compliance officer is to ensure the compliance with all local laws and rules. The role of the ethics officer is to promote a discussion of how, although there are no laws related to the issue, the company will maintain its purpose of, for example, protecting the environment. And that is why ethics is so important for sustainable development, because it is the search for an ideal, the reflection on the possibility of a new path in function of an ideal, the pursuit of a purpose: "Business ethics seeks to understand the ethical contours and devise principles of right action for, business activity" [9].

For the purpose of this investigation we will thus focus on ethics, and when in certain citations or references the word "compliance" appears along with "ethics", that is because in practice and within the literature, both concepts often appear together. Nonetheless, what we seek is the evidence of ethics.

\subsection{Methods Used}

Our approach is qualitative since what is intended here is not to know what, but essentially how, to perceive through the signs and the interpretation of these signs, the way ethics is lived within these organisations and the relevance given to it. To put in other words, our purpose is "to discover rather than test variables"[10].

We believe, as Treviño et al (2014) have put it, that this approach "allows for more detailed, exploratory accounts of how individuals perceive and cope with the challenges they face"[5]. Despite this according to these authors this approach and sensibility rarely appears in top-tier journals. Another study developed by McLeod et al[11] confirmed the same lack of qualitative and empirical studies in the field of business ethics. The study, which includes an analysis of 45 journals listed in the Financial Times, with no restriction of year of publication, allowed the conclusion that " $87 \%$ of all studies on the ethical climate construct utilized survey methods whereas qualitative techniques, archival, and experimental designs only make up 7,7\%, and $2 \%$, respectively"[11]. 
The methodology used is Grounded Theory, a specific methodology developed by Graser and Strauss (1967) "for the purpose of building Theory from data" [12]. According to this theory, the researcher himself is the starting point of the analysis through his initial idea and the choice of the material to be analysed.: "In Grounded Theory, the analysis begins as soon as the first bit of data is collected"[13]. Finally, the researcher's mission is to have openness so that the theory can thus emerge.

For this reason, a literature review is not initially carried out in Grounded Theory, although it can be used to clarify research questions as it was done here, but "After the first interview (s) or observation (s), the researcher will turn to questions and concepts derived from the analysis of the data"[10]. At the end we return to the literature review to see how the conclusions reached are referred to by other researchers.

It is important to mention that the used methodology, influenced the article's structure, resulting on the joint appearance of the findings and conclusions of each analysed subject. Then there will be a section of general conclusions and discussion.

\subsection{The Sample and the Elements of Analysis - Methodological Approach by Steps}

We take as a reference the European companies that were included in the 2019 World Most Ethical Companies's list from the Ethisphere Institute, which distinguishes "companies that exemplify and advance corporate citizenship, transparency, and the standards of integrity"[14].

To be part of The World Most Ethical Companies' list companies have first to apply, answering a questionnaire which includes aspects such as Governance; Ethics program - Structure, Oversight, Responsibility, and Resources; Due Care; Written Standards - Policies and Procedures; Compliance; Training; Awareness and Communication; Detection, Monitoring, and Auditing; Enforcement, Discipline, and Incentives; Measurement of Ethical Culture; Third Party Management; Citizenship, Sustainability, and Corporate Responsibility and Leadership and Reputation.

Since this questionnaire aims to verify if the applicant company is fits to be a part of the list, we considered that there would be an underline a paradigm of excellence in the management and incorporation of ethics in the company. We analysed the questionnaire looking for this paradigm, looking for patterns and we drew a portrait an ethics oriented company from it.

This constructed portrait was used as a comparative point for the analysis of the institutional discourse on the theme, used in the management and sustainability reports of the distinguished companies, to find practical examples of ethics incorporation and identifying problems. We later felt the need to validate and complement the conclusions we reached, and we included other documentation such as the corporate website pages, in what relates to ethics.

Note that this is another of the Grounded Theory's characteristics: the sample should not be completely closed and defined beforehand, and throughout the analysis the researcher "decides what data to collect next and where to find them, in order to develop theory as it emerges"[12].

All of the Ethisphere 2019 index European companies (18) were selected. Regarding the sources, we analysed each company's annual report, preferably from 2018 or, when not yet available, from 2017. It is worth noting that the name of the company's report was not always the same. Some companies call it "management report", others "report and accounts", and in other cases, "integrated report".

Sustainability reports were also analysed (where there was an integrated report, including data on nonfinancial information, there was generally no sustainability report). The ethics ombudsman report or the chief ethics and compliance officer report were also analysed (although companies that publish such reports are rare).

These sources were chosen because they are companies' official communication tools to some of their most relevant stakeholders such as shareholders and investors. That is, we considered that, since ethics is relevant to these companies, the approach taken to it should be included in these reports. On the other hand, regarding the management report, this is something all companies are obliged to have and that, at least in European companies, must also include non-financial information covering aspects such as human rights and corruption [15]. The sustainability report by definition covers the economic, environmental and social impacts of the company's business and "also presents the organization's values and governance model, and demonstrates the link between its strategy and its commitment to a sustainable global economy" [16]. 
It should be noted that we omit the name of the companies from the reports' excerpts presented in the findings, because these are only illustrative examples, and the name of the company could divert us from our focus. For that reason, companies appear only identified by a number.

The first object of analysis was, as mentioned, the Ethics Coefficient Survey (The Ethisphere ${ }^{\circledR}$ Institute, 2019) which consists of about 200 questions that have been screened to result in a set of questions focused on the relevance of ethics, and that could be used to draw up the portrait of model company - a company, not only with excellent management, but that also assumes as their mission to seek an ethical conduct.

Questions that have been withdrawn: those with an open response, for which we had no data to know which answer would correspond to the Ethisphere model of excellence, questions whose answer depended on Company's characteristics, such as the number of workers, those with a scope that went beyond the experience and management of ethics in the company and involved aspects such as sustainability strategy, or some corporate governance questions such as the number of independent directors.

After this screening we came to a set of about 130 questions, which were divided into themes in order to find a connection with ethics relevance.

We favored life-related questions, for example Q4A12: - Select the types of interactions the ethics and compliance function has with other functional groups in your companyll, minus questions related to the existence of instruments such as policies or codes. We made this choice because the existence of these elements does not imply that its effectiveness. "Effectiveness is determined by the manner in which it is developed, implemented, and embedded॥[3].

\subsection{The Coding}

The definition of the first codes came from Ethisphere questionnaire's analysis and our model company portrait.

The reports analysis was made using the MAXQDA program, a content analysis software that allowed us to more systematically grab information, make links between codes and do lexical searches within documents allowing to see and analyse blocks of text. The lexical analysis that included words like ethics or integrity was carried out, not to verify the frequency since we are in the scope of the qualitative analysis, but to be able to analyse more accurately and in detail the company's approach regarding aspects that we considered relevant.

To define the reports' analysis indicators, a mixed approach was used: first a closed, deductive approach, with a priori definition of codes based on the company portrait and the identification of aspects that could be clear, objective and valid in that portrait for any of the companies' signs of relevance given to ethics. After and throughout the reports'analysis we used an open and inductive approach, with definition of codes a posteriori based on the uniqueness of the data, and the relationships between indicators as predicted in the Grounded Theory.

In addition to these indicators and considering that we were analysing reports, the principles of GRI concerning the quality of the information [17] were also taken into account. The principles concerning the definition of content were not taken into account as we were analysing concrete and previously defined aspects.

\subsection{The Reliability of Information}

Given the approach and methodology followed, it is especially relevant to ensure the credibility of the information.

Firstly, it is important to mention the choice of sources. We have already argued about the relevance of management and sustainability reports as an official and privileged source for some of companies' most relevant stakeholders. However, after reviewing the reports, we were still unsure about companies' approach to ethics and felt a need to find other sources of information. This search and the sources identified as a result of the assumed strategy are what Charmaz calls theoretical sampling, "a strategy for seeking and collecting pertinent data to elaborate and refine categories in your emerging theory"[18]. 
And when should we consider that this search for new information should stop? Exactly when there is no new information, when the sources consulted to validate the data, only brings us to information that we essentially had already found. This is called theoretical saturation: "the point at which gathering more data about a theoretical category reveals no new properties nor yields any further theoretical insights about the emerging grounded theory" [18]. For us, this point was reached in the companies' websites when nothing new was found that had not already been identified in the reports.

We also followed Lincoln and Guba's recommendations [19] regarding the three activities capable of increasing the probability that credible findings will be produced: "prolonged engagement, persistent observation, and triangulation".

By prolonged engagement is meant "the investment of sufficient time to achieve certain purposes: learning the 'culture', testing for misinformation introduced by distortions either of the self or of the respondents, and building trust"[19]. In other words, it is intended to ensure that the researchers know the context, a fundamental aspect for the content analysis to be performed: "Is not possible to understand any phenomenon without reference to the context in which it is embedded"[19].

Indeed, analysing business discourses on ethics, perceiving inconsistencies and identifying value aspects could hardly be done without a good knowledge of ethics in the business context. In this sense, it should be noted that one of the researchers supported several companies in the development of ethics programmes over 10 years and followed the activities and challenges of various people responsible for managing ethics closely. Additionally, researchers have extensive experience in reading and analysing sustainability reports and are well aware of the specifics of this type of communication. This proximity that allows us to know the context, frame and interpret the information that is transmitted also has a danger for which we need to be aware: The danger of "going native" [19].

The possibility of "going native", proximity bias, was especially clear to us at the time all the coded elements had been seen and it was detected that one of the companies, the best known of the investigator responsible for this task, had a clearly higher number of coded segments. Under this light and to verify the objectivity of coding, lexical analysis was also used as well as self-coding (coding done automatically by MAXQDA) of all segments with the word ethics. In each of the companies the proportion remained the same. Automatic coding and lexical searching were then also used as a means of verifying coding exemption in this and other situations.

The second activity proposed by Lincoln and Cuba is "persistent observation", whose purpose is "to identify those characteristics and elements in the situation that are most relevant to the problem (...) That focusing also implies sorting out irrelevancies - the things that do not count" [19]. This activity was carried out first in the questionnaire analysis and identification of the issues to be considered for the portrait and was taken into account throughout reports' analysis.

The last activity is triangulation that must be done "using different sources, different methods, and sometimes, multiple investigators"[19].

Regarding sources, in addition to the management and sustainability reports, we studied other information from the company, such as websites and, later, we crossed that information with the work and conclusions of other researchers. There were also different methods in terms of information gathering, coding (using self-coding as "contradictory") and even in terms of information analysis, where at times quantitative information processing to validate perceptions in terms of content analysis was used.

Finally, the fact that we are four researchers with different backgrounds (engineering, philosophy, economics and sociology) and all have reviewed the information, reinforces the credibility of the analysis.

\section{FINDINGS}

The first finding is the company model portrait drawn from the 2019 Ethisphere Institute questionnaire's analysis. Indicators built from the portrait are the starting point for analysing the reports, the following findings, and the conclusion regarding the relevance of ethics to companies. Finally, we present what seems to be for us the key factor in promoting true ethical relevance in companies. 


\subsection{Model Company Portrait}

The Model Company has one person in charge of ethics management (Q4A.2). This person may eventually accumulate the function with other functions (Q4A.3), but if this happens it is important that the company assumes that there is another person which ensures the operational management and which will also be heard by the top. (Q4A.4 and 5).

The ethics responsible reports to the Chairman or the CEO, and has the power and independence necessary to recruit, propose new conduct policies, make the budget (a budget that allows to effectively develop the different programme dimensions) (Q4A.11). Due to the relevance of his role the ethics responsible is invited to various company's management committees namely to give input on the development of products and services, as well as to comment on corporate strategy. He or she has formal interactions with different areas. (Q4A. 11 and 12).

The Board follows the culture issues in the company. This is done through different sources. The person in charge of ethics makes regular presentations to the board and the ethics committee that meets regularly to discuss different aspects of the ethics program. (Q4A.15 to 24). An ethical risk analysis following the usual protocols for risk analysis is part of the ethical programme (Q4E.7 to 11).

The company provides ethics training to all employees (Q4D.1 to 7) according to a previously defined plan for several years and according to specific themes and targets. In addition to this planned training, there is also extraordinary training in response to Identified misconduct or at management request.

There is special training for managers (Q4D.10 to 13) to support them in the task of encouraging and promoting ethical conduct. This training is given to new managers and periodically to existing managers, being a significant part in face-to-face mode. Training is mandatory for all managers and includes topics such as incorporating ethics in decision making, handling complaints reporting, how and when to talk ethics with the team, identifying and preventing retaliation, and even conducting evaluation interviews (Q4D.7).

Board members also receive training on their specific code (Q3.14 to 17) or at least on the company's code of ethics. This training takes place regularly, at least every two years. Training topics are varied, but necessarily include the company's ethical risks and trends from the industry and law standpoint.

In addition to training there is also an ethics communication plan (Q4D.15 to 19). The plan is multiyear and is made with different departments' collaboration. There is a definition of media and topics for each audience, in particular, work area, functional level and geography are taken into account. The company uses several communication modalities in order to communicate ethics messages, such as: Company e-bulletin or newsletter emails, Intranet portal dedicated to ethics, Podcasts, Company-wide initiatives or programs blogs, posters or videos (Q4D.18).

In addition to general communication for all workers, proximity communication is developed by managers. To support managers in the development of this communication, the company provides them with tools such as question \& answer kits, previously prepared discussions, mail templates or suggestion of communication moments (Q4D.19).

The ethics communication plan includes communication from the CEO and other company officers (Q4D.20). Top management communication can be materialised in testimonials at the opening of the training, a welcome email, code opening and less formal interventions such as testimonials for blogs, or articles in the company magazine and includes examples of situations they have experienced (Q4D .22). Also, the person responsible for ethics include examples of real world ethical or compliance dilemmas or issues in his or her communications (Q4D.23).

To encourage good practice, the company includes ethical conduct in employee performance appraisal and makes it a bonus component for managers. A peer recognition system (Q4F.7) is also developed.

The company has a reporting system that ensures anonymity if desired and in countries where permitted (Q4E.1 and 2). The system follows each report made to the investigation phase (Q4E.3, 4, 5). The company has written procedures for investigating and provides specific training for the people conducting those investigations. At the end of each investigation feedback is gathered from the people involved in the end of process (Q4F.1 to 3). 
Regarding detected bad practices, the company always makes an analysis of the aspects that were in its origin. This analysis is done using a specific methodology (Q4F.4 and 5). To detect any potential retaliation for reporting misconduct, the company monitors different aspects such as changes in satisfaction, increased days off, substantial changes in performance appraisal, changes in company function or status, dismissals. (Q4F.6).

Regarding the reporting of bad practices (Q4E.6), in addition to reports made to the Board informing on the origin of the complaint, theme and outcome, a communication is also made to the entire $\mathrm{C}$ suite, employees and even, appropriately, for the general public.

The company regularly establishes an evaluation of its ethical program (Q4E.7 to 11). This evaluation includes aspects such as ethical risk assessment, culture, employee awareness of rules and regulations or the complaint management system, the relationship between ethics and other functions, training, communication, the complaint handling system, the processes to encourage ethical performance, and the processes to prevent retaliation.

Culture evaluation is done through surveys, interviews, focus groups or other means including the visit by the person responsible for ethics to the different geographies. Survey themes include knowledge of grievance channels, opinion on ethical leadership, facility/confidence to file a complaint, observation of bad practices, pressure to compromise ethics (Q4G.3) (Q4G.12).

As a way to promote continuous improvement of the program and identify bad practices that might not have been reported, the company also conducts exit interviews (Q4F.8). Company leadership and reputation are also assessed using different methodologies (Q7.2) and company leaders are recognised as promoters of ethics and integrity within and outside the industry (Q7.6 and 7).

\subsubsection{Obligatory Passage Points of an Ethics Oriented Company}

After the model company portrait, we tried to summarise the signs of ethical relevance in topics that were observables in corporate communications through the analysis of reports. Inspired by the Actor Network Theory [20], We name these topics obligatory passage point and we use them to difine the first codes

Relevance codes:

- Function name: although Ethisphere has several designations as a possibility, we considered that the choice of name is not innocuous and somehow gave us a sign about the relevance given to ethics;

- Relevance given to the function: position autonomy and participation of the person responsible in the strategy, management committees and interaction with different areas;

- Formal relevance: relevance of ethics to the company according to official discourse;

- Board and top engagement: participation in communication and training;

- Management engagement: training and support tools that enable managers to discuss ethical issues with employees;

- Search for improvement: whether or not a program evaluation is made and what aspects are evaluated.

Transparency codes:

- Existence of a Report on Complaints - reported aspects

- How the report is made - we felt that the very form of reporting is a choice in some way related to the relevance given to ethics and the visibility of that relevance in different acts of the company.

\subsection{Companies' Analysis}

\subsubsection{Who Manages Ethics?}

According to Ethisphere's global analysis [21] most companies, about 80\%, have the word Ethics, or Compliance, in the function name, but there are many other designations. The results we have reached 
for Europe are similar: a wide range of designations, as well as the persistence of cases in which ethics accumulates with other functions, which happens in two situations in our sample and which can be a sign of a "non-recognition that running an ethics and compliance program is a full-time job and one that is worthy of the appropriate title."[22].

In any case, what prevails is a function that results from the combination of the name ethics with compliance. The use of the word ethics in an isolated way is much rarer (19\%).

The compliance function associated with ethics seems to value it as it has a much higher percentage of "Chief" title than ethics alone (Figure 1). When the person is solely responsible for ethics, the position name is more inaccurate such as the Office of the Ethics Ombudsman, Ethics Delegates or Ethics Officer, without the word Chief.

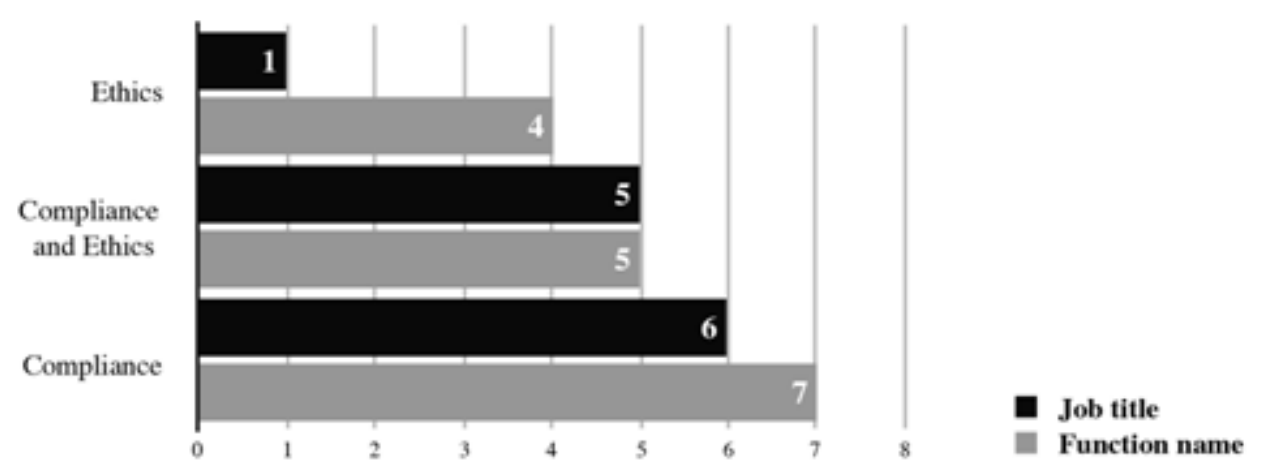

Figure 1 - Number of chief titles versus function names

In other words, there seems to be a devaluation of ethics and perhaps also a difficulty in understanding what the role and relevance of the ethics officer may be.

Another fact that seems to corroborate this idea is that even though most companies have ethical codes or guides, when it comes to the function, only 8 have the name ethics even in conjunction with compliance. This means that in half of the cases the company has a code of ethics that is managed by a compliance officer. Of course, a compliance officer can verify compliance with code of ethics commitments as if it were a regulation: "measures for compliance with the Code of Ethics, which includes (...) actions to ensure compliance with the rules on market abuse and separation of activities, and (v) management of the ethics mailboxes (Company 8), but a code of ethics should not have a verification of its application in the same way as a regulation does.

Another sign of the focus on compliance, may be the background of the one who's responsible for that function most of the times (86\%) a legal one. This can be seen as normalif you think of the function having responsibility to verify compliance with laws and regulations, but not if you think of the function having the responsibility to support reflection and decision-making in the company according to a particular purpose and set of values, "the key element of business ethics" [8].

This prevalence of legal education (almost $90 \%$ in total) can also lead to the feeling of unpreparedness referred by Treviño et al (2014), ethics and compliance require different knowledge and skills and "it is difficult to find an individual that can successfully lead both ethics and compliance."[8].

Neff and Gresham[23], both compliance officers in large companies, state that ethics and compliance are two areas with different missions that should coexist in the company in an articulated manner. To explain it the authors start from the fraud triangle (Cressey 1953) - racionalisations, opportunity and pressure - and state that in order to avoid frauid there are three functions involved: compliance, ethics and leadership as a whole: "(a) Ethics should focus on reducing an employee's ability to rationalise misconduct; (b) compliance should focus on shrinking the opportunity for misconduct; and (c) leadership should focus on reducing unhealthy pressure to perform or meet certain targets [23].

Once again we have ethics linked to reflection, promoting workers' ability to reflect and take responsibility, and in this sense, more than the legal area per se, could be an area like philosophy (a 
very minority among those responsible of ethics in our sample) the most appropriate to promote reflection on potential ethical issues in different areas.

\subsubsection{Relevance Given to Function}

According to our company model portrait the ethics and compliance function is invited to participate in the reflection of different areas including corporate strategy. This is the paradigm and, according to Ethisphere, this also seems to be the reality: "in $91 \%$ of honoree companies, the function is included in sales and marketing meetings outside of purely deploying training, and in 89 percent they have formal input into corporate business strategy"[21].

In our sample we also found examples of this relevance: "the Senior Vice President Chief Compliance and Integrity Officer, is responsible for developing the company's corporate responsibility program. (...) Goal setting is carried out in close collaboration with business operations based on identified corporate responsibility aspects. (...) In 2018 the Senior Vice President Chief Compliance and Integrity Officer also became part of the Executive Management team (Company 6).These were found, but in rare situations.

What we saw in the reports, in most cases, especially when we are talking about a person responsible for ethics only, is a narrower field of action: [the ECO] Provides training and supports employees in making decisions that are ethical, legal, and consistent with our values. Investigates any concerns about potential breaches of our Code of Conduct (Company 12). A function distant from business and sometimes conflicting with it: "despite the noble purposes of their role, ECOs face internal legitimacy challenges - great numbers of employees and leaders are "non-believers" in part because Ethics and Compliance are often seen as clashing with dominant business imperatives"[24].

Additionally, in some cases, a devaluation is visible regarding the autonomy agreed upon when compared to other functions: "The Ethics Ombudsman's Office is responsible for supporting the General and Supervisory Board and the Executive Board of Directors regarding the definition, communication, implementation and assessment of objectives, policies and management instruments of corporate ethics. (...) The Sustainability Department's mission is to analyse, propose and guarantee the Group's sustainability strategy "(Company 5).This means that the person responsible for ethics does not define, but rather supports the definition of strategy and instruments, while those responsible for other areas, in this case, sustainability, propose a strategy and propose instruments.

Perhaps the most striking case of lack of relevance is the almost widespread absence of the ethics officer in the management committees where the most relevant topics for the company are discussed, an absence that was not guessed by companies that are part of an index called the World Most Ethical Companies, and has in its matrix ethics as one of the most relevant issues.

\subsubsection{Ethics Formal Relevance}

According to the materiality matrices of the studied companies, ethics tops concerns of both companies and stakeholders.

To notice that in the matrices, companies mostly use the word ethics alone or in combination with integrity, and sometimes in combination with other concepts. In other words, we have companies that mostly have codes of ethics that are managed by compliance directors and that refer, in terms of relevance, not compliance but ethics.

It's important to highlight that since the matrix is built with stakeholders input, the question of the word used acquires a different relevance; it can no longer be viewed merely as a possible arbitrary companies' choice - it is completely different to have stakeholders requiring companies to comply with the law than to have stakeholders demanding more ethical behavior. For some stakeholders, compliance may even be taken for granted, while ethics is the goal.

Ethics also emerges in all companies' values, although mostly translated in the word integrity, appearing either as a value name or as an explanation in 12 of 18 companies. Integrity often appears defined as honesty and fulfilment of promises, and it arises linked to a need: to earn the trust of customers. Only one company presents ethics as a transversal subject, present in all values, and highlights the complexity and the need for questioning: Integrity - "Because acting with integrity is vital to building and maintaining trust and good relationships. Respect - Because what we do has an 
impact on many different stakeholders. Courage - Because ethical questions are rarely simple but must be addressed; Transparence - Because we must always be sincere and able to justify our actions and decisions" (Company 11).

The same company gives us another sign of relevance which is consistency, continuity of concern with the theme and level of people involved in it: Each year, Ethics Day has enabled the Group to explore its key ethical principles. (...) In 2018, all members of the Executive Committee also took part in the same exercise. Since the first-ever Ethics Day was held in 2009, the participation rate has more than tripled worldwide, with thousands of questions being asked each year (Company 11).

The formal relevance given to ethics arises in different ways in corporate discourse, such as in priorities' presentation: Six challenges have been defined as crucial: human rights and duty of vigilance, data security and privacy, business integrity, workplace safety and access to health care, and carbon neutrality (Company 15), or as a need for business continuity, "If we do not continue to develop and implement the right processes and tools to manage our enterprise and instill our culture and core values into all of our employees, our ability to compete successfully and achieve our business objectives could be impaired (company 1).

It also emerges as an imperative and a last resort when there is no law: Under Irish law, the duties of directors and officers of a company are generally owed to the company only. Shareholders of Irish companies do not generally have rights to take action against directors or officers of the company (...). Directors of an Irish company must, in exercising their powers and performing their duties, act with due care and skill, honestly and in good faith with a view to the best interests of the company (company 1).

Of course, we also find signs of the relevance given to ethics without using the word. We find essentially these "evidences" in sustainability discourses; in fact sustainability often appears as something bigger, an umbrella under which ethics is placed: "To be a responsible company, all aspects of sustainability must be respected. Business ethics and integrity, tax and legal compliance, human rights and environmental care are therefore integral components in driving prosperity. It provides us with a solid foundation on which to build trust and demonstrate leadership towards sustainable development (Company 18). But the truth is that without ethical reflection, the development of moral reasoning, sustainability runs the risk of a case-by-case approach, a checklist that meets the recommendations of the sector, rater or index.

But even taking into account the indirect approach of sustainability, we would say that in general and in big business issues ethics is kind of forgotten, it does not come up regularly when talking about core themes such as product development: "Product development is influenced by customers' needs, legislation, changes in society and new technologies (Company 18)

\subsubsection{Board and top management engagement}

A clear sign of ethics' relevance to the organisation is the board involvement, and one of the ways to show this involvement is the reports' opening messages: "The Board of Directors places great importance on respecting (company's name)'s ethical principles - Integrity, Respect, Courage and Transparency - and more generally its Code of Ethics. In 2018, the Senior Vice-President and Chief Ethics Officer presented the ethics policy and the initiatives taken in this field, as well as their results. The Board considers the policy to be an integral part of (company's name) s growth model, supports its implementation and regularly measures the progress made (Company 11).

"But rarely in these opening messages does a reference to problems and less successful aspects appears, which would be a sign of balance and also of transparency. However, we find notes regarding a reflection at the highest level on aspects with an ethical dimension, such as: "The Board devotes most of its time to strategic issues to foster and accelerate the Group's transformation into a more universal, more digital and more sustainable [company]. (Company 11)."

From a communication point of view, we have also not found many signs of Board or Direction involvement. However, some references appear: "Our Country Managing Director Advisory Council, comprising leadership representation from across the globe, participates in quarterly Conduct Counts calls to provide perspective, offer guidance on local needs, create geographic synergy and serve as a sounding board for priorities and new initiatives"(Company 1). 
Regarding ethics training at the top-level, references are also rare and "there was a training initiative in 2018 directed to the Board of Directors regarding the Compliance System and the structure, bodies and tasks thereof." (Company 8); or "Anti-Corruption and Bribery training was provided to the Board of Directors and parts of the executive management team" (Company 6).

\subsubsection{Management Engagement}

In the Model Company featured in the portrait, "Training is mandatory for all managers and includes topics such as incorporating ethics in decision making, dealing with complaints reporting, how and when to talk ethics with the team, identifying and preventing retaliation, and even conducting evaluation interviews." We found several signs of that, more with managers than with the board or top management, as if there was somehow a delegation of the role of inspiring ethics and creating an ethical climate. The question that remains in the air is whether managers feel inspired without top management's influence.

Signs of further training for managers: in addition, all managers are assigned a quarterly "Values in Action" training which requires them to hold a discussion session with their team based on prescribed scenarios that pose a variety of ethical dilemmas. All scenarios are based on cases from the Integrity Helpline or risks identified through internal audit or management review (company10). This means a specific training to the context of the company, reinforcing its relevance.

"This additional training is referred to by several companies and there is an assumption that managers have a role -as multipliers to further raise awareness of compliance. Their feedback is analysed carefully and used to initiate additional training sessions or other measures, if necessary 2 (Company 16). “

Managers' involvement can also be seen in the level of demand that is required of them while interacting with teams: "Some employees felt they were listened to but were not kept informed of what happened to their suggestion or feedback (...) In response to the findings, the Ethics and Compliance team is working with leaders across the company to address areas for continuous improvement and maintain commitment to the highest ethical standards" (Company 13).

\subsubsection{Ethics Program Evaluation}

The Model Company is expected to evaluate its ethics program, including aspects such as "the ethical risk assessment, the culture, the employees' knowledge of compliance aspects or the complaint management system, the relationship between ethics and others functions within the company, training, communication, the complaint handling system, processes to encourage ethical performance, and processes to prevent retaliation."

We only found evidence of such coverage and even greater coverage in one company. In this company the following aspects are evaluated: complaint management, ethical risk management, ethical leadership, works environment, knowledge and trust in management tools, trust, transparency, integrity, diversity and non-discrimination and external evaluation through raters like Ethisphere itself (Company 5). The breadth of this evaluation also represents a holistic view of ethics.

This does not mean that other companies do not have a holistic view of ethics, it just means that they do not want or do not consider those additional aspects relevant to report.

One aspect most companies report about is "ethical culture" evaluation. They mostly use the word ethics, although in some cases, in alignment with the company focus, they refer "a culture of compliance". The assessment of ethical culture is often referred to within risk management as a sign of relevance, a conscious or unconscious assumption that if you want to mitigate risk you need to go beyond compliance: "Understanding the underlying factors that influence employees to behave ethically or unethically is essential to efficiently prevent unethical conduct "(Company 6).

In the evaluation results, however, one continues to feel, just as in the complaint report, a lack of accuracy: Our people are really clear about our vision, our values and our way - everything we think, feel, say and do (company13). An analysis of the survey results leads to a number of specific measures to improve situations or problems that have been detected (Company 8). 
What do we Talk about when we Talk about Ethics? A Research Journey through the World Most Ethical Companies

\subsubsection{Communication and Transparency}

The transparency issue fits into the company's ethical conduct on two levels. On the one hand, a company that does not account for what legitimately matters to its stakeholders is in some way not acting ethically (unless it has specific reasons justifying it), on the other hand, the aspects that the company considers important to report and the rigor with which it does so are also a sign, namely in compliance with the GRI principles regarding information quality.

One of the principles is balance: to talk about what went well and what went wrong. We have already mentioned that in reports' opening messages there are few CEOs or Chairmen who report less successful aspects, but in the reports' body text we find some failure examples: Despite the best preventative measures, we are not always able to prevent breaches of law or violations of regulations at the Company (Company 16). In 2018, as a result of our audits we encountered seven cases where we saw potential risk of forced labor (Company 12).

Some companies admit having a difficulty in ensuring compliance within its commitments: Our size and scale present significant management and organizational challenges. It might become increasingly difficult to maintain effective standards across a large enterprise (...) For example, employee misconduct could involve the improper use of our clients' sensitive or confidential information or the failure to comply with legislation or regulations regarding the protection of sensitive or confidential information (Company 1). This balance can also be a defense by the company that clarifies the limits of its liability. As for the other principles, clarity and accuracy, we found many opportunities for improvement, starting with the complaints report.

\subsubsection{Complaints Report}

Regarding reporting and in addition to what emerges in our standard company portrait - informing about the source of the complaint, theme and outcome - one must also mention the requirements of the GRI guidelines on this specific subject: "The description of internal and external mechanisms for reporting concerns about unethical or unlawful behavior (...) The total number of concerns expressed during the reporting period, including the percentage that were addressed, resolved and found to be unsubstantiated during the reporting period, and the types of misconduct reported The level of satisfaction of those that used the reporting mechanisms"[25].

Most companies are far from this standard, perhaps along with the presence of the head of ethics on management committees, this is where the gap between reality and the portrait is most visible. According to Ethisphere there are only $28 \%$ of companies that make aspects related to the reported concerns available to the public and even less have a report exclusively dedicated to ethics, $6 \%$ [22]. In our sample, only one company has a specific report and 39\% percent do not report (Figure 2).

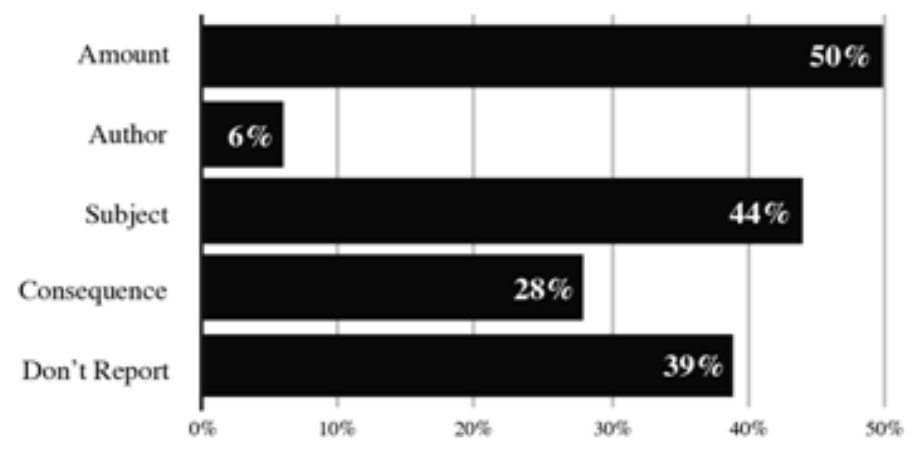

Figure 2 - Concerns Report \%

Only one company gives examples explaining the reflection process to arrive at the determination of consequences, and only 2 companies present the number, theme and consequences with multi-year data. Note that despite the reports made by about $60 \%$ of companies, one can notice some lack of accuracy materialised in the use of words like "proportional" which does not let us understand which sanctions are imposed: In confirmed cases, we impose systematic sanctions that are proportionate to the act and the guilt of the perpetrator and are in line with applicable legal provisions (Company 16). 


\section{CONCLUSION AND DISCUSSION}

To sum up, from the ethics management model advanced by Rossouw and Van Vuuren (2017), the perception that emerges from our analysis is that most companies are still in a "compliance mode", with an approach centered in risk management and avoidance of penalties, few are in an "integrity mode", promoting ethical behavior, and only one show signs of a "totally-aligned mode", where "ethics is ingrained in corporate purpose and identity"[26] being part of the reflection on strategy in different business areas.

It is true that all companies have, somehow, almost all the mechanisms referred to in the Ethisphere index. Our concern is exactly around this "somehow". For exemple, training: with what content? In person or online? How regularly, and how long ago? With or without evaluation?

In most cases, this seems to be a time of compliance and the usefulness of ethics as a guarantee of trust, as well as a time of lack of coherence. Companies have highly developed formal system, perhaps even excellent ones, with all the instruments, including someone responsible for the area and an evaluation of the program with accountability and they still do not have a presence of ethics in strategic matters, nor in the reflection on the different company areas. The person responsible for ethics is not invited for management committees and is not given the title of chief. This non-inclusion can have a huge impact on the person's legitimacy vis-à-vis the other workers of the company. We say this based on our personal experience of following up on ethics management in companies, the "prolonged engagement" that Lincoln and Guba [19] refer to as fundamental for analysing information. This perception is in line with the findings of Treviño et al [24], who reports that ethics officers develop their work with a perception of challenge and a need for support.

In risk matters, this inconsistency is also visible and starts from the fact that in most of the companies the risk and its relevance continue to be measured in a strictly financial logic. This approach is not unique to companies: in formal documents on ethical risk such as the Ethics Risk Handbook, ethical risk is presented primarily with a focus on financial impact: "ethics risk is a dimension of risk in the same way that legal, operational, IT, finance and HR risks are. While the non-management of ethics risks could give rise to as many, if not more, reputational and financial costs for a company as any other type of risk, it warrants equal attention. As such, ethics risk is a component of the broader organisational risk framework" [27]. This means that it is on the financial consequence that the impact is measured, and not, for example, on the consequence for society or the environment, in a logic of purpose.

In this line of reasoning, although companies present ethics as being at the center of their concerns, in practice there is little room for ethical risk other than compliance, whenever things don't result in fines or penalties.

A feeling that also prevails from reading of the reports is inconsistency in the use of the word ethics; the perception of lack of clarity about what is and what may be the role of ethics. The use of the word ethics also seems sometimes to have the intent to take weight off and put things at a certain level of ambiguity. Even in the index name, the "World Most Ethical Companies" looking at the questionnaire content might refer compliance, but it would be a big responsibility to list World's Most Compliant Companies or even World Most Integral companies

It is as if companies do not know what ethics is, nor what to do with it, and use the words according to the public, and thus, according to the analysed discourse, being compliance the one that is truly relevant.Companies seem to forget that ethics is often their only resource and the basis of security in the context in which we live, characterised by volatility, where laws and rules become obsolete or change from country to country in a global market, with increasing uncertainty, complexity and conflicting values and heterogeneity of stakeholders. In fact, and as Treviño and Brown [28] pointed out, being ethical is not easy. This is one of the myths surrounding ethics that eventually gives rise to the low relevance given to it by comparison to compliance. The complexity of ethics begins with the difficulty of seeing ethical issues: "Rarely do decisions come with waving red flags that say, 'Hey, I'm in an ethical issue!'”[28] and seeing it is a necessary precondition for action.

For all this and because "most adults [including senior executives] in industrialised societies are at the "conventional" level of cognitive moral development, and less than twenty percent of adults ever 
reach the "principled" level (...) that most adults are looking outside themselves for guidance in ethical dilemma situations"[28] it is essential to convey a clear sign of ethics' relevance for the company and to have someone or a group of people that can support decision making and help create an ethical climate.

Perhaps the difficulty in finding a place for ethics has to do with the lack of a purpose that acts as a compass for ethical reflection: "For the will to exist, a system of motives must be formed"[29]. This idea of purpose is now beginning to reach companies.In one of the companies analysed there is even a document about the purpose and in it, the changes that are intended from this reflection are evident: Being aware of this, we wish to continue advancing and extending this business philosophy, which is why we have engaged in a process of reflection to define a clear and long-term corporate purpose (Company 8).

The need for a purpose is also pointed out by Weller "Without this explicit intention, it can be easy to understand how compliance practices focused on regulatory risk management and CSR practices focused on value creation may result in a company not accounting for some of the ethical middle ground that falls outside of their siloed interpretations of ethics in practice and lead to managers missing important ethical considerations in their companies"[7].

But in many cases it seems to us that the purpose is still developed from an utilitarian and risk management perspective and that it emerges as a necessity, as we can guess in the words of Larry Fink, president of one of the biggest investment firms: "Purpose guides culture, provides a framework for consistent decision-making, and, ultimately, helps sustain long-term financial returns for the shareholders of your company"[30]. Ultimately, this is still the main reason: purpose is not yet a driver for internal reflection to be enforced in each act.

In any case, this purpose could be the materialisation of the values that all companies claim to have and that may be the starting point for a cross-sectional reflection. Luc de Branbadere defines values with the following characteristics: "Something we defend even if the market sanctions it; something we want to convey to our children, something that goes through the test of time, that makes us get up in the morning and whose absence causes us indignation"[31]. When something is felt like that in a company, naturally everything has to be questioned in the face of those values and ethics becomes naturally present.

This conviction-driven approach is the only one that allows ethics to naturally enter into the operations and day-to-day business development, because, let's face it: there is no business case for ethics in this holistic way from a company point of view. We lose time, money, freedom... There is only a business case for ethics in a society point of view. And that is what makes this such a difficult issue, it seems the opposite of what a manager was "programmed" for, we get used to accepting that "ethics must be left at the door of the company" [32].

We live fascinated by wealth which "is ultimately the great and universal cause of the corruption of our moral feelings" [33] and there's a need for a "new ideological references, that would recreate a sustainable structure different from the western economic model. This is because the values of the western model are incompatible with the sustainability of the environment[34].

This new ethics can only be assumed in the business world if it is believed, as Adam Smith argued in his Theory of Moral Sentiments, that "the economy must be at the service of the good and the people" [32] and that "the basis of moral laws does not consist of any simple and mechanical utilitarian ethics" [33].

For companies, ethics is not a question of business case but one of purpose, of will. And faith is a risk as it is something that somehow goes beyond the scope of reason. When we are within reason we do not believe, we know: we know what is the most efficient, what increases profitability and what shareholders want. The purpose, the values, the ethics as a way of achieving them are not within the scope of reason, they are within the scope of belief, and "There is no rational continuity possible. Because what is believing, if not being faced with what cannot be believed? It is in this sense only, absolutely paradoxical, that the risk can be taken, by making a leap that the reason refuses to do"[35].

And eventually we have to assume that from a company standpoint, considering how we are used to understand companies, there are no rational arguments that fully justify the inclusion of ethical reflection in the strategy and in all areas. It is necessary for managers to believe against all evidence 
What do we Talk about when we Talk about Ethics? A Research Journey through the World Most Ethical Companies

that it must be possible to make a company flourish by following the path of ethics irreducibly and this is a dissent from the current standard, but "belief is a dissent"[35].

\section{REFERENCES}

[1] E. Mitleton-Kelly, "Complex Systems and Institutions: The Implications of the Sciences of Complexity for Organisational Design," in To the Man with a Hammer... Augmenting the Policymaker's Toolbox for a Complex World, London: Bertelsmann Stiftung, 2016.

[2] P. Wesarat, M. Y. Sharif, and A. H. Abdul Majid, "Role of Organizational Ethics in Sustainable Development: A Conceptual Framework,” Int. J. Sustain. Futur. Hum. Secur., vol. 5, no. 1, pp. 67-76, 2017.

[3] M. Kaptein, "Understanding unethical behavior by unraveling ethical culture," Hum. Relations, vol. 64, no. 6, pp. 843-869, 2011.

[4] Aristóteles, Ética a Nicomaco. Lisboa: Quetzal Editores, 2004.

[5] Treviño Linda Klebe and Nelson Katheribe A., Managing Business Ethics Straight Talk about How To Do It Right. wiley, 2014.

[6] A. Watson, "Ethics vs. compliance: Do we really need to talk about both?," Law.com, 2014. [Online]. Available: https://www.law.com/almID/52de821b150ba0ed2200004f/. [Accessed: 23-Aug-2019].

[7] A. Weller, "Exploring Practitioners' Meaning of 'Ethics,' 'Compliance,' and 'Corporate Social Responsibility' Practices: A Communities of Practice Perspective," Bus. Soc., pp. 1-27, 2017.

[8] L. Groenewald and G. Dondé, "Ethics and Compliance Handbook," The Ethics Institute and Institute of Business Ethics (IBE), 2017.

[9] J. Moriarty, "Business Ethics," The Stanford Encyclopedia of Philosophy, 2017. [Online]. Available: https://plato.stanford.edu/entries/ethics-business/. [Accessed: 27-Aug-2019].

[10] J. Corbin and A. L. Strauss, Basics of Qualitative Research : Techniques and Procedures for Developing Grounded Theory". SAGE Publications Ltd, 2008.

[11] M. S. McLeod, G. T. Payne, and R. E. Evert, "Organizational Ethics Research: A Systematic Review of Methods and Analytical Techniques,” J. Bus. Ethics, vol. 134, no. 3, pp. 429-443, 2016.

[12] B. G. Glaser and A. L. Strauss, The Discovery of Grounded Theory - Strategies for qualitative reserch. New Brunswick and London: AldineTransaction, 1967.

[13] J. Corbin and A. Strauss, "Grounded Theory Methodology: Procedures, Canons, and Evaluative Criteria," Qual. Sociol., vol. 13, no. 1, pp. 3-21, 1990.

[14] The Ethisphere ${ }^{\circledR}$ Institute, “About the Ethisphere Institute," 2019. [Online]. Available: https://ethisphere.com/about/. [Accessed: 23-Aug-2019].

[15] Parlamento Europeu, "Diretiva 2014/95/UE, do Parlamento Europeu e do Conselho, de 22 de outubro de 2014.," J. Of. da União Eur., vol. 2014, no. 2, pp. 330/1-330/9, 2014.

[16] GRI, "About Sustainability Reporting," GRI, 2019. [Online]. Available: https://www.globalreporting. org/information/sustainability-reporting/Pages/default.aspx. [Accessed: 13-Oct-2019].

[17] Global reporting Initiative, "G4 Sustainability reporting Guidelines - Reporting Principles and Standards Disclosures," p. 97, 2015.

[18] K. Charmaz, Constructing Grounded Theory A Practical Guide Through Qualitative Analysis. London, New York, New Deli: SAGE Publications Ltd, 2006.

[19] Y. S. Lincoln and E. G. Guba, Naturalistic Inquiry. Newbury park, California: SAGE Publications Ltd, 1985.

[20] M. Callon, "Some elements of a sociology of translation: domestication of the scallops and the fishermen of St Brieuc Bay,” Power, Action Belief A New Sociol. Knowl., no. 32, pp. 196-233, 1986.

[21] The Ethisphere $囚$ Institute, "Leading Practices and Trends from the 2018 World's Most Ethical Companies - Volume 2: Structuring and Resourcing Your Ethics and Compliance Program Effectively," vol. 2, p. 16, 2018.

[22] The Ethisphere ${ }^{\circledR}$ Institute, "Leading Practices and Trends from the 2018 World's Most Ethical Companies - Volume 3: Maximizing the Effectiveness of Managers," 2018.

[23] C. A. Neff and J. J. Gresham, "The difference between ethics and compliance - and why understanding the difference is critical to successful leaders," J. Pract. Bus. ethics, vol. 30, no. 1, pp. 1-5, 2016.

[24] L. K. Treviño, N. A. Den Nieuwenboer, G. E. Kreiner, and D. G. Bishop, "Legitimating the legitimate : A grounded theory study of legitimacy work among Ethics and Compliance Officers," Organ. Behav. Hum. Decis. Process., vol. 123, pp. 186-205, 2014.

[25] Global Reporting Initiative, "Part 2 - Implementation Manual," G4 Sustainability Reporting Guidelines. p. 262, 2014. 
[26] The Ethics Institute and the Ethics Practitioners' Association, The Ethics Office Handbook. The Ethics Institute, 2018.

[27] L. Van Vuuren, "Ethics Risk Handbook,” Ethics Inst., pp. 1-77, 2016.

[28] L. K. Treviño and M. E. Brown, "Managing to be ethical: Debunking five business ethics myths," Acad. Manag. Exec., vol. 18, no. 2, pp. 69-81, 2004.

[29] L. Coimbra, "O criacionismo," in Leonardo Coimbra Obras Completas I (1903-1912), Lisboa: Imprensa Nacional Casa da Moeda, 2004, p. 382.

[30] L. Flink, "LARRY FINK'S 2019 LETTER TO CEOS Purpose \& Profit,” BlackRock, 2019. [Online]. Available: https://www.blackrock.com/corporate/investor-relations/larry-fink-ceo-letter. [Accessed: 12Sep-2019].

[31] L. Brabandere, Les mots et les choses de l'entreprise - des repères philosophiques essenciels pour les dirigents. 2012.

[32] A. Cortina, Etica de la Empresa. Madrid: Trotta, 1994.

[33] J. M. Moreira, A Contas com a Ética Empresarial. Cascais: Principia, 2002.

[34] G. Oliveira de Paula and R. N. Cavalcanti, "Ethics: Essence for Sustainability," J. Clean. Prod., vol. 8, pp. 109-117, 2000.

[35] A. Dufourmantelle, Éloge du Risque. Paris: Éditions Payot \& Rivages, 2011.

\section{Authors' Biography}
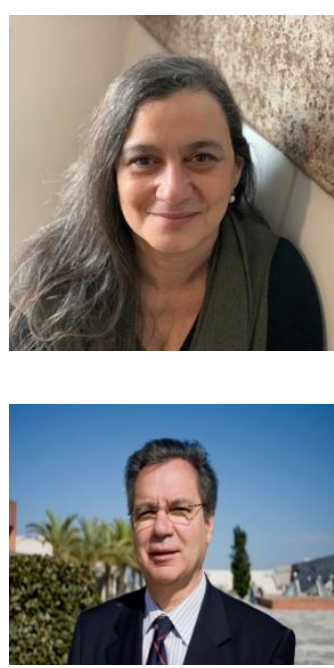

Ana Roque, has been a consultant, facilitator and researcher in business ethics and corporate social responsibility for 25 years. She was co-founder of two companies linked to sustainability and develops projects to promote awareness in this area through theater and publications aimed at the general public. She has a degree in Philosophy, Advanced Education in Ethics of Organizations, a Master in Corporate Social Responsibility, Accounting and Social Audit. Since 2010 she has been regularly documenting and writing case study's related to ethics management.

José Manuel Moreira, is a full professor at the University of Aveiro, Portugal. He received a first degree in Economics in 1974 from the University of Lisbon, Portugal, a first degree in Philosophy in 1980 from the University of Oporto, Portugal, and his PhD degree in 1992 in the philosophy and methodology of Economics of F. A. Hayek from Universidad Pontificia Comillas, Spain. He has published several books on business ethics and public administration and articles on the history, philosophy and methodology of economics, the market economy and the role of the entrepreneur, social and political philosophy, public policy and ethics.

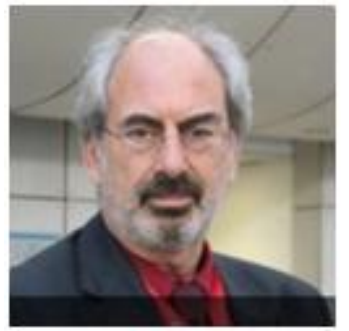

José Figueiredo, is a professor at the Engineering and Management Department of IST - University of Lisbon, a researcher at CEG-IST, Engineering and Management Research Center, and he is an Electronics Engineer with an MBA in Information Management and a PhD in Industrial Engineering. Being always involved in university teaching he started two small companies in the information technologies sector. He taught Project Management and communication skills for many years and now, the last six years, he is involved with Project for the Engineering and Management Master on Energy. $\mathrm{He}$ published several papers in international journals, international edition book chapters, and conference proceedings.

Rosana Albuquerque is Assistant Professor in the Department of Social Sciences and Management at UniversidadeAberta, where she is responsible for teaching subjects in the areas of Sociology and Social Policy. With a degree in Social Policy, she completed a master's degree in Intercultural Relations and a PhD in Sociology. She is also a researcher at the Center for the Study of Migration and Intercultural Relations / CEMRI (since 1994), 
What do we Talk about when we Talk about Ethics? A Research Journey through the World Most Ethical Companies

where she has developed studies on migrant associations, civic participation and citizenship, in the Portuguese and European context.

Citation: Ana Roque et al. "What do we Talk about when we Talk about Ethics? A Research Journey through the World Most Ethical Companies" International Journal of Managerial Studies and Research (IJMSR), vol 8, no. 1, 2020, pp. 60-75. doi: http://dx.doi.org/10.20431/23 49-0349.0801007.

Copyright: (C) 2020 Authors. This is an open-access article distributed under the terms of the Creative Commons Attribution License, which permits unrestricted use, distribution, and reproduction in any medium, provided the original author and source are credited. 